\title{
Psychiatry for the person and its conceptual bases
}

\section{George Christodoulou, ${ }^{1}$ Bill Fulford ${ }^{2}$ and Juan E. Mezzich ${ }^{3}$}

\begin{abstract}
'Professor of Psychiatry, National and Kapodistrian University, Athens; President, Hellenic Centre of Mental Health; Chair, WPA Standing Committee on Ethics; Chair, WPA IPPP Conceptual Component

2Professor of Philosophy and Mental Health, University of Warwick; Co-Director, Institute of Philosophy, Diversity and Mental Health, University of Central Lancashire; Special Advisor for Values-Based Practice, Department of Health, London

${ }^{3}$ Professor of Psychiatry and Director, International Center for Mental Health, Mount Sinai School of Medicine, New York University; President of the World Psychiatric Association (WPA); Chair, WPA Institutional Program on Psychiatry for the Person (IPPP), email juanmezzich@wpanet.org
\end{abstract}

\begin{abstract}
The 2005 General Assembly of the World Psychiatric
Association (WPA) established the Institutional Program on Psychiatry for the Person (IPPP) in response both to a recognition of our profession's historical aspirations and to recent international developments in clinical care and public health. These considerations point to the relevance of a comprehensive understanding of health and the centrality of the person in the delivery and the planning of healthcare. The IPPP's goals can be summarised as the promotion of a psychiatry of the person (of the totality of the person's health, both ill and positive), by the person (with clinicians extending themselves as full human beings), for the person (assisting the fulfilment of the person's life project) and with the person (in respectful collaboration with the person who consults). Operationally, the IPPP has four components: conceptual bases, clinical diagnosis, clinical care, and public health. What follows is an initial review of the IPPP's conceptual bases and an outline of its emerging activities.
\end{abstract}

\section{Initial exploration of conceptual bases}

Many physicians lament that modern medicine (and psychiatry) is dominated by a fragmentation of care and a hyperbolic dependence on technology. To specialise in a specific area of science and clinical practice is both inevitable and desirable. The quantity of knowledge is so great that competence and expertise in a specific area is a necessity. So, fragmentation of care is, to a certain degree, inevitable. Dependence on technological achievements has also become inevitable in recent times and the admirable technological progress that has occurred has contributed immensely to the advancement of medicine and psychiatry.

It would, therefore, be naive and unproductive to deny the importance of these two developments. However, the Hippocratic dictum 'nothing in excess' is applicable in this case as well (Jouanna, 1999). Overspecialisation has reached, in some cases, a degree where it deprives physicians of their bio-psychosocial approach, and excessive dependence on technology has reduced the physician from the status of 'equal to God' (professed by Hippocrates) to that of a mere technologist. Issues related to ethics and to the identity of the physician are relevant here.
An approach that would integrate excellence in certain clinical areas with scientific and technological advances, within a framework of holistic medicine, and that would refocus our attention on the person has become a necessity. The concept of 'person' is, of course, a protean one. It changes geographically and diachronically and it is subject to cultural, political, religious, socio-economic and ethical considerations.

The need for holism in medicine was strongly advocated by Ancient Greek philosophers and physicians. Socrates and Plato taught that 'if the whole is not well it is impossible for the part to be well' (Christodoulou, 1987) and such was also the position of Aristotle.

These ideas are re-emerging in our times, not only within the Western medical tradition but also in a number of other rich traditions around the world. For example, Ayurvedic and Chinese medical traditions, ancient and still practised, with sound philosophical, experiential and experimental bases, focus on the patient's total health rather than only on disease. Both articulate a comprehensive and harmonious framework of health and life, and promote a highly personalised approach for the treatment of specific diseases and the enhancement of quality of life (Patwardhan et al, 2005). Concern for the centrality of the person is also being adopted by influential international health organisations (Presidential Commission on Mental Health, 2003; WHO European Ministerial Conference on Mental Health, 2005). The psychosomatics movement, with its emphasis on the totality of the person, has contributed considerably to the holistic and personified perspective, and so has the emphasis on positive mental health, in other words, on the factors and approaches that keep people healthy, in contrast to the factors that produce illness.

The context of each person is closely linked to identity. Nobody lives in a vacuum. This is exemplified by a dictum of the philosopher Ortega y Gasset, 'I am I and my circumstance'.

The holistic approach has been extended to include the environment. It is being increasingly recognised that, in addition to the social environment, the natural environment is a very important contributor to health on a group basis but also on an individual basis. Thus the teachings of Hippocrates, with the emphasis he gave to the protective and healing powers of nature, are re-emerging in our times. Holism on an individual level has recently been extended to include broadness in the provision of psychiatric services, that is, the integration of mental health in general health and public health practice (Herrman et al, 2005). This kind of perspective results from 
the realisation that mental illness and physical illness are fundamentally similar; indeed, they differ in no respect other than clinical expression, and consequently should be managed both in hospital and in the community in a similar manner, thus minimising stigmatisation of those with a psychiatric illness and fragmentation of the provision of care.

Another trend towards personified medicine has emerged with the introduction of the concepts of recovery and resilience (Anthony, 1993; Allott et al, 2002; Amering \& Schmolke, 2007). These concepts support the involvement, active participation and responsibility of people to protect themselves from illness and to promote and maintain health and recovery from illness.

These developments are emerging in response to many deficiencies in general health and mental healthcare that have been identified not only by a number of clinicians, ethicists and philosophers (Strauss, 1992; Bloch, 2005; Sharfstein, 2005) but also by health administrators and policy makers (Office of the Surgeon General, 1999; Department of Health, 2005a,b).

Clearly, a different, more comprehensive, more humanistic, more holistic and more person-centred perspective is needed (Antonovsky, 1987; Christodoulou, 1987; Ricoeur, 1990; Sensky, 1990; Fulford et al, 1995; Cloninger, 2004; Mezzich, 2005).

Additionally, a more person-centred approach on the part of the physician is strongly encouraged (Cox et al, 2006; Department of Health, 2005c). This touches on the ethics of the medical profession. Indeed, consideration of the patient as a person and not as a carrier of illness is a fundamental ethical obligation of the physician. This is consistent with the 'respect for autonomy' in the 'principle-based ethics' theory (Beauchamp \& Childress, 1994) and with each of the wide range of other ethical theories that support healthcare (Fulford et al, 2002).

The above considerations led to the preparation and then the establishment of the IPPP by the WPA General Assembly in 2005. Furthermore, this perspective is highlighted in this triennium's presidential theme and is informing the overall topics of many congresses of the WPA and its member societies (Mezzich, 2007a). As part of this, a person-centred integrative diagnostic model is being designed (Mezzich \& Salloum, 2007). Another crucial development has been the engagement of patient/user groups, including those critical of psychiatry, reaffirming the dialogical bases of our profession (Mezzich, 2007b). The IPPP is emerging as a long-term initiative that aims at refocusing the objectives of psychiatry, in particular, and, potentially, medicine at large on the needs of persons.

\section{First steps of the IPPP conceptual component}

Several key concepts underlying the IPPP are being analysed as follows:

a broad concept of health, including illness or pathological aspects as well as positive ones, such as adaptive functioning, protective factors and quality of life

$O$ the concept of 'person' and its key characteristics, including autonomy, history, context, needs, values and life project, in addition to illness experience

the historical evolution of person-centred concepts in psychiatry and medicine o the philosophy of science underlying broad conceptualisations of health and person-centred care

$\checkmark$ the ethical implications of a person-centred psychiatry and medicine, relevant to the raison d'être of the field and the profession (this may offer a valuable approach to dealing with stigmatisation against persons in psychiatric care)

o the biological (genetic, molecular, physiological) bases for a psychiatry and medicine for persons, including an individualised understanding of illness, health and care processes

o the phenomenological, learning and other psychological bases of person-centred care

the socio-cultural framework of a broad concept of health and the plural meaning of 'a person' in the medical field

$O$ the value of and need for comprehensive diagnosis and care, as well as integration of services to achieve a personcentred psychiatry and medicine

o the conceptual basis for engaging interactively all stakeholders in the health field for the development and implementation of person-centred concepts and procedures, including persons and families in healthcare, health professionals and planners, industry, social advocates, and so on.

The conceptual issues listed above are being investigated through the preparation of the following set of papers, to be assembled as a prospective special issue or supplement of an international journal:

o historical perspectives

philosophy-of-science perspectives

$O$ ethics and values perspectives

o biological perspectives

o psychological and phenomenological perspectives

o social, cultural and spiritual perspectives

perspectives of health stakeholders and partners

o psychiatry of the person in literature

psychiatry of the person in art

psychiatry of the person in film.

Additionally, other journal papers as well as books relevant to the conceptual bases of the IPPP are being prepared.

As the general theoretical groundwork is completed, conceptual analyses will be extended to strengthen the development of the clinical diagnosis, clinical care and public health components of the overall programme.

\section{Concluding remarks}

The initiative on psychiatry for the person represents a paradigmatic shift in our profession and field, refocusing its central objectives on what can be argued is psychiatry's (and medicine's) fundamental soul. The importance and complexity of this endeavour require pointed attention to its conceptual bases. This effort should not only firmly anchor our perspectives but also open creative paths to extend their reach.

\section{References}

Allott, P., Loganathan, L. \& Fulford, K. W. M. (2002) Discovering hope for recovery. Canadian Journal of Community Mental Health, Special Issue 'Innovation in Community Mental Health: International Perspectives', 21, 13-33.

Amering, M. \& Schmolke, M. (2007) Recovery - Das Ende der Unheilbarkeit. Psychiatrie Verlag. 
Anthony, W. (1993) Recovery from illness. The guiding vision of the mental health service systems in the 1990s. Psychosocial Rehabilitation Journal, 16, 11-23.

Antonovsky, A. (1987) Unraveling the Mystery of Health. Jossey-Bass.

Beauchamp, T. \& Childress, J. (1994) Principles of Biomedical Ethics (4th edn). Oxford University Press.

Bloch, S. (2005) The art of psychiatry. World Psychiatry, 4, 130-134. Christodoulou, G. N. (ed.) (1987) Psychosomatic Medicine. Plenum Press.

Cloninger, C. R. (2004) Feeling Good: The Science of Well-Being. Oxford University Press.

Cox, J., Campbell, A. V. \& Fulford, K. W. M. (eds) (2006) Medicine of the Person: Faith, Science and Values in Health Care Provision. Jessica Kingsley Publishers.

Department of Health (2005a) New Ways of Working for Psychiatrists: Enhancing Effective, Person-Centred Services Through New Ways of Working in Multidisciplinary and Multiagency Contexts (Final report 'but not the end of the story'). Department of Health.

Department of Health (2005b) Independence, Well-Being and Choice: Our Vision for the Future of Social Care for Adults in England. Department of Health.

Department of Health (2005c) Creating a Patient-Led NHS: Delivering the NHS Improvement Plan. Department of Health.

Fulford, K. W. M., Ersser, S. \& Hope, T. (eds) (1995) Essential Practice in Patient-Centred Care. Blackwell Science.

Fulford, K. W. M., Dickenson, D. \& Murray, T. H. (eds) (2002) Healthcare Ethics and Human Values. An Introductory Text with Readings and Case Studies. Blackwell.

Herrman, I. T., Saxena, S. \& Moodie, R. (eds) (2005) Promoting Mental Health: Concepts, Emerging Evidence, Practice. World Health Organization.
Jouanna, J. (1999) Hippocrates (trans. M. B. Debevoise). Johns Hopkins University Press.

Mezzich, J. E. (2005) Positive health: conceptual place, dimensions and implications. Psychopathology, 38, 177-179.

Mezzich, J. E. (2007a) Psychiatry for the person: articulating medicine's science and humanism. World Psychiatry, 6, 1-3.

Mezzich, J. E. (2007b) The dialogal bases of our profession: psychiatry with the person. World Psychiatry, 6, 129-130.

Mezzich, J. E. \& Salloum, I. M. (2007) Towards innovative international classification and diagnostic systems: ICD-11 and person-centered integrative diagnosis. Acta Psychiatrica Scandinavica, 116, 1-5.

Office of the Surgeon General (1999) Mental Health: A Report of the Surgeon General. Department of Health and Human Services, US Public Health Service.

Patwardhan, B., Warude, D., Pushpangadan, P., et al (2005) Ayurveda and traditional Chinese medicine: a comparative overview. EvidenceBased Complementary and Alternative Medicine, 2, 465-473.

Presidential Commission on Mental Health (2003) Achieving the Promise: Transforming Mental Health Care in America. Final Report. DHHS Pub N: SMA-03-3832. Department of Health and Human Services.

Ricoeur, P. (1990) Time and Narrative. University of Chicago Press.

Sensky, T. (1990) Patients' reactions to illness. BMJ, 300, 622-623.

Sharfstein, S. S. (2005) Presidential address. Advocacy of our patients and our profession. American Journal of Psychiatry, 162, 2045-2047.

Strauss, J. S. (1992) The person - key to understanding mental illness. Towards a new dynamic psychiatry, III. British Journal of Psychiatry, 161 (suppl. 18), 19-26.

WHO European Ministerial Conference on Mental Health (2005) Mental Health Action Plan for Europe: Facing the Challenges, Building Solutions. Helsinki, Finland, 12-15 January 2005. EUR/04/5047810/7

\title{
European service perspectives for people with intellectual disabilities and mental health problems
}

\section{Geraldine Holt, ${ }^{1}$ Helen Costello ${ }^{2}$ and Nick Bouras ${ }^{3}$}

\begin{abstract}
${ }^{1}$ Consultant Psychiatrist, King's College London, Institute of Psychiatry, Estia Centre, London, UK, geraldine.holt@kcl.ac.uk ${ }^{2}$ Research Coordinator, King's College London, Institute of Psychiatry, Estia Centre, London, UK, email helen.costello@kcl.ac.uk ${ }^{3}$ Professor of Psychiatry, King's College London, Institute of Psychiatry, Estia Centre, London, UK, email Nick.Bouras@kcl.ac.uk
\end{abstract}

Suk ervices for people with intellectual disabilities, in the UK as elsewhere, have changed dramatically over the last 30 years; deinstitutionalisation has probably been the largest experiment in social policy in our time. The vast majority of people with intellectual disabilities, their families and carers have benefited from having a better quality of life as a result of deinstitutionalisation. However, much still needs to be done to integrate this population more into society and to ensure they are offered the appropriate supports to meet their needs.

There has been considerable variation nationally in the provision of services, particularly for those people with intellectual disabilities who have additional mental health problems. There is a relative lack of provision in some regions, despite the fact that evidence-based practice has shown that there is a high prevalence of undiagnosed and untreated mental disorder among people with intellectual disabilities. We also know that mental illness among people with intellectual disabilities often presents in atypical ways and that it may coexist with a wide range of neurodevelopmental disorders. Finally, we are aware that many people with intellectual disabilities have impaired communication and hence are unable to describe subjective symptoms; these individuals are particularly at risk of being overlooked or misdiagnosed.

Despite the uneven provision of services for people with intellectual disabilities, an international consensus has emerged and most countries have been trying to develop relevant policies and services for them. Although models of care are changing, the pace of change varies dramatically between countries. This issue's thematic papers provide an insight into services for people with intellectual disabilities and mental 